\title{
As novas configurações da educação e dos materiais educacionais digitais: multiletramentos em uma proposta editorial transmídia
}

\author{
Camila de Castro Castilho \\ Universidade Estadual de Campinas
}

\begin{abstract}
Resumo
Qual o papel das editoras nas novas configurações da educação? Direcionando essa reflexão para a elaboração de materiais educacionais digitais, o presente trabalho discute a importância de as editoras oferecerem materiais que proponham a integração das tecnologias às metodologias de ensino. Para exemplificar, apresentamos a produção de um material transmídia, planejado com base na pedagogia dos multiletramentos.

Palavras-chave: multiletramentos, transmídia, material didático digital
\end{abstract}

\begin{abstract}
What is the role of the publishers in new configurations of education? Directing this reflection to the production of digital learning materials, this article discusses the importance of the publishers offering materials that propose the integration of technologies with teaching methodologies. As an example, we present the production of transmedia material whose planning was based on the pedagogy of multiliteracies.
\end{abstract}

Keywords: multiliteracies, transmedia, digital learning materials

\section{INTRODUÇÃO}

O uso das tecnologias da informação e da comunicação (TICs) nas práticas de sala de aula já faz parte da antiga discussão sobre a necessidade de repensar e reestruturar os sistemas de ensino e adotar novos modelos educacionais. O modelo que vigora na educação formal atual é o mesmo do século XIX. Alguns professores ainda transmitem conteúdo, enquanto o papel dos alunos limita-se à recepção e memorização dessas informações, segmentadas por disciplinas, com temas dissociados de sua realidade.

Desde a segunda metade do século XX, esse modelo vem sendo fortemente questionado e algumas iniciativas buscam adotar novos modelos pedagógicos em busca de uma mudança paulatina. A necessidade de uma revolução educacional efetiva é derivada das novas configurações da educação. A democratização do ensino trouxe a diversidade para a sala de aula. Esta diversidade é ampla e vai além da diversidade de idade, gênero, étnica ou/e classe socioeconômica. 
A diversidade de linguagens também faz parte das novas configurações da educação. A multiplicidade de linguagens não é apenas decorrente do uso das TICs em sala de aula, mas também da presença de diferentes textos, impressos, digitais ou compostos de múltiplas linguagens, que exigem capacidades e práticas de compreensão e produção.

Devido à existência de uma “nova lógica” imposta inclusive pelas TICs, identificamos e reconhecemos a necessidade de uma educação para os multiletramentos. Segundo Roxane Rojo (2012), é necessário pensar em práticas letradas multiculturais e multimodais que fazem uso de diferentes mídias e, consequentemente, de diversas linguagens, incluindo aquelas que circulam nas mais variadas culturas.

Portanto, o modelo educacional vigente não atende os anseios e as necessidades dessa diversidade. Assim, os professores são convidados a assumir uma postura que leve em conta a ressignificação dos modelos educativos, inclusive alinhados ao uso das novas tecnologias em sala de aula. Diante desse quadro, fica a dúvida: qual o papel do livro didático nesse contexto? Que tipo de material didático deve ser oferecido?

Ampliando e direcionando a discussão para a produção editorial digital, o desafio está na elaboração de materiais que estejam de acordo com as novas configurações da Educação. O presente artigo propõe-se a incentivar a produção de materiais que estimulem metodologias de ensino com tecnologia, sobretudo as embasadas na pedagogia dos multiletramentos, e apresenta uma proposta transmídia produzida ${ }^{1}$.

\section{AS NOVAS CONFIGURAÇÕES DA EDUCAÇÃO E OS DESAFIOS DO MERCADO EDITORIAL}

Consolidado desde 1930, o mercado de livros didáticos vem sofrendo uma série de mudanças tentando acompanhar as demandas educacionais. O contexto de transição atual do mercado acabou fragilizando economicamente as editoras. Ainda assim, quem determina a demanda por livros didáticos são os professores e gestores na adoção. Por esse motivo, esses educadores são referência para as principais editoras de didáticos.

Ainda que muitos professores sejam adeptos de uma pedagogia transmissiva, por falta de formação ou por ideologia, as demandas por alterações na proposta pedagógica

\footnotetext{
${ }^{1} \mathrm{O}$ presente artigo foi concebido para sistematizar os conhecimentos adquiridos durante as produções de material didático digital e as discussões realizadas da disciplina de Multimodalidade e Construção de Sentidos no Meio Digital, ministrada pela Profa. Dra. Roxane Rojo, na Universidade Estadual de Campinas, no segundo semestre de 2014.
} 
dos materiais didáticos são diretas e indiretas. Com o objetivo de acompanhar as mudanças, as editoras optaram por incentivar o uso das tecnologias da informação e da comunicação em sala de aula, investindo na produção de conteúdos digitais.

Áudios, vídeos, simuladores, jogos educacionais e infográficos são produzidos ou selecionados por uma equipe técnica com o apoio de editores e, em raras ocasiões, de um coordenador pedagógico ou de especialistas das respectivas áreas do conhecimento. Isso justifica a principal crítica ao material digital oferecido pelas editoras que, na sua maioria, é reprodução de informações e de conteúdos dos livros impressos.

Portanto, assim como os educadores, as editoras são impulsionadas a assumir uma nova postura; uma que leve em conta a ressignificação dos modelos e das produções, principalmente do ponto de vista educacional. Espera-se que sejam apresentadas novas propostas pautadas na diversidade, por meio de uma dimensão mais ética e de responsabilidade social, de modo a reconhecer, complementar e enriquecer as diferentes realidades e concepções de conhecimento, além de orientações de como mediar práticas letradas que fazem uso de diferentes mídias e, consequentemente, de diversas linguagens, ou seja, uma proposta para os multiletramentos.

De acordo com Roxane Rojo (2012), multiletramentos são práticas letradas multiculturais e multimodais que fazem uso de diferentes mídias e, consequentemente, de diversas linguagens, incluindo aquelas que circulam nas mais variadas culturas. Os multiletramentos incluem, ainda, procedimentos, como gestos, e capacidades de leitura e produção:

\footnotetext{
“(a) eles são interativos; mais que isso, colaborativos; (b) eles fraturam e transgridem as relações de poder estabelecidas, em especial as de propriedade (das máquinas, das ferramentas, das ideias, dos textos [verbais ou não]); (c) eles são híbridos, fronteiriços e mestiços (de linguagens, modos, mídias e culturas)" (ROJO, 2012, p.23).
}

Mas, será que uma produção editorial digital para os multiletramentos é possível? O presente artigo apresenta uma proposta transmídia para os multiletramentos como uma possibilidade.

\section{O CONTEXTO DE UMA PRODUÇÃO EDITORIAL DIGITAL}

A produção editorial digital do Grupo IBEP Educação a ser apresentada possui um contexto muito específico: a produção de um livro digital com objetos educacionais digitais para os anos iniciais do Ensino Fundamental I. 
Criado em 1965, o grupo é genuinamente brasileiro. Seus fundadores apostavam no potencial dos livros didáticos, em crescente expansão nos anos de 1960, ocupando uma faixa em torno de $30 \%$ dos livros publicados. O grupo conseguiu promover o acesso ao livro didático a todas as camadas sociais, além de criar edições específicas para diferentes regiões do país.

Para continuar acompanhando as tendências do mercado editorial, o Grupo IBEP Educação monta uma equipe editorial digital, ainda que pequena e com recursos financeiros limitados, com o objetivo de cobrir as necessidades desse tipo de produção e acompanhar o crescimento e as demandas de materiais didáticos digitais das escolas particulares e dos editais do Programa Nacional do Livro Didático (PNLD).

Tendo em vista as profundas transformações na educação, o novo núcleo trouxe novas ideias e teorias, buscando disponibilizar ferramentas teóricas e práticas aos educadores de modo a capacitá-los a discutir com seus alunos as transformações e refletir sobre o impacto dessas mudanças na vida e na sociedade, e, assim, contribuir para a formação de cidadãos críticos, aptos a filtrar, interpretar e produzir conhecimento.

\section{ABORDAGENS TEÓRICAS}

As propostas são amparadas por conceitos e teorias de pensadores das áreas de educação, comunicação e ciências sociais, nas legislações e nos documentos do Ministério da Educação, em especial as Diretrizes Curriculares Nacionais (DCNs).

O sociólogo Marco Silva (2006) contribuiu com a ideia de que é preciso romper com o modelo baseado na transmissão de conteúdos e inovar através de uma mudança radical no sistema de ensino com base na Teoria da Educação do Parangolé, fundamentada na interatividade. Inspirada na obra de Hélio Oiticica, a teoria propõe uma participação ativa dos alunos e maior interação tanto no ambiente da sala de aula como nas atividades e práticas do processo de ensino-aprendizagem, que devem incluir, entre outras possíveis estratégias, a prática de múltiplas experimentações, as formulações de situações-problemas e a mobilização de experiências de diferentes conhecimentos que podem ser apresentados através de diferentes mídias e por meio de diversas linguagens, o que potencializa a presença dos multiletramentos em sala de aula.

Neste contexto, os educadores têm como desafio compreender e dialogar com uma geração de alunos chamados "nativos digitais”. A expressão foi cunhada pelo 
pesquisador em educação Marc Prensky (2001) e serve para diferenciá-los dos “imigrantes digitais”, aqueles que não nasceram em um contexto completamente digital, mas em um ambiente mais analógico e linear, tendo que se adaptar às mudanças trazidas pela cultura digital. Por esse motivo, os letramentos digitais dos docentes se fazem urgente.

Buzato (2006) utiliza esse conceito no contexto da cultura digital, apresentando os letramentos digitais. Tratam-se, portanto, de aquisições indispensáveis aos imigrantes para poderem se apropriar e fazer uso das novas tecnologias e dos recursos que a cultura digital disponibiliza inclusive como ferramentas na sala de aula.

Devido à existência de uma “nova lógica” imposta inclusive pelas TICs, incentivamos a identificação e o reconhecimento da necessidade de uma educação para multiletramentos. Segundo Roxane Rojo (2012), é necessário pensar em práticas letradas multiculturais e multimodais que fazem uso de diferentes mídias e, consequentemente, de diversas linguagens, incluindo aquelas que circulam nas mais variadas culturas.

Para relacionar o conceito de multiletramentos com os modelos educacionais e as metodologias de aprendizagem, é importante retomar a pergunta que propôs o conceito: “o que é apropriado para todos [os alunos] no contexto de fatores de diversidade local e de conectividade global cada vez mais críticos?” (Grupo de Nova Londres, 2006 [2000/1996], p. 10).

Em busca de respostas a essa pergunta, os autores incorporam duas multiplicidades ao conceito: (1) de linguagens e de mídia e (2) a multiplicidade e diversidade cultural local características das populações hoje, conforme afirma GarcíaCanclini (2005; 2006), pois se tratam de textos multimodais próprios dos novos letramentos.

O pesquisador Jay Lemke (2010) traz para a discussão a teoria de que as práticas educativas que envolvem os multiletramentos devem considerar e integrar habilidades de autoria multimidiática, analisar criticamente as diversas mídias, prever estratégias de exploração do ciberespaço e buscar o desenvolvimento de habilidades de navegação nos meios digitais.

Lankshear e Knobel (2007) contribuem para a proposta com o conceito de novos letramentos, que compreende letramentos que apresentam digitalidade e, principalmente, um novo ethos, ou seja, um novo modo de pensar e de agir; um 
comportamento que prioriza a interatividade, a coautoria, a colaboração e a distribuição do conhecimento.

A cultura multimídia e digital é uma cultura de massa, fruto da globalização e da sociedade de consumo, que é padronizada, homogênea e pasteurizada. Por esse motivo, é imprescindível que a proposta editorial ofereça a oportunidade de o educador trabalhar com letramentos críticos, com o objetivo de tornar os alunos indivíduos capazes de lidar com os textos de diferentes gêneros e discursos de maneira a perceber seus valores, intenções e efeitos sentidos, trazendo essas práticas para a sala de aula.

Ainda, é fundamental que se tenha as Diretrizes Curriculares Nacionais (DCNs) como base, pois são elas que orientam o planejamento curricular das escolas e dos sistemas de ensino, norteando seus currículos e conteúdos mínimos. As DCNs concebem as novas tecnologias como aliadas do currículo e reconhecem a importância da intencionalidade de seu uso para que a escola se torne um ambiente de inclusão digital e de produção e utilização crítica de conteúdos digitais.

E, por fim, a proposta "transmídia”, criada a partir da teoria de Henry Jenkins (2009). O termo emprestado foi trazido e contextualizado para a produção de materiais educacionais. Assim como a proposta de Jenkins, o material apresenta uma situaçãoproblema, que se desenrola por meio de diferentes mídias e, consequentemente, diversas linguagens. Cada mídia possui autonomia e apresenta a integração de conteúdos de diferentes disciplinas, tratando o tema transversal de forma distinta, contribuindo para a discussão e para a aprendizagem dos alunos sobre o assunto. No contexto da produção editorial, o termo transmídia também deve traduzir uma produção híbrida e, desta forma, deve integrar, transpassar e perpassar os materiais impressos e digitais.

\section{UMA PROPOSTA EDITORIAL TRANSMÍDIA É POSSÍVEL?}

A partir da base teórica apresentada, foram criadas três propostas transmídias para cada ano do Ensino Fundamental I. Cada proposta transmídia parte do livro didático impresso, elaborado pela perspectiva transversal, que possibilita a interdisciplinaridade. 


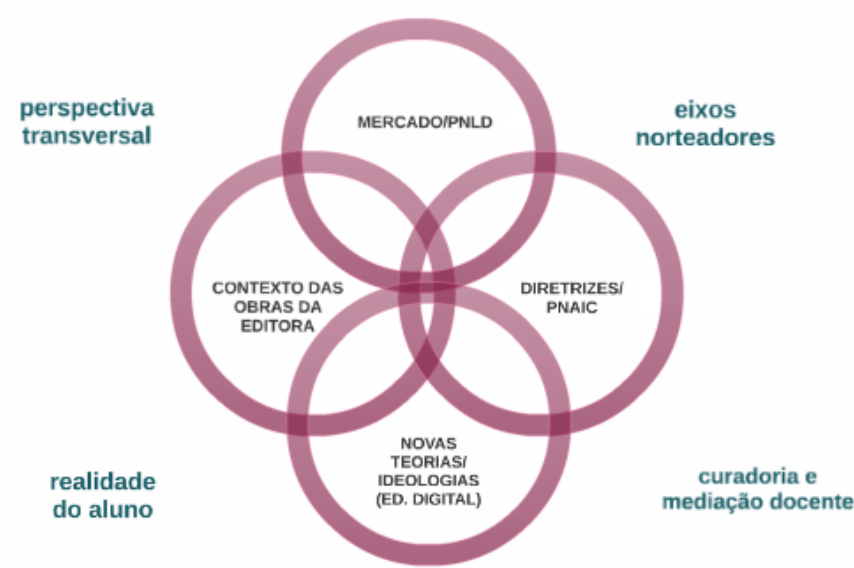

Figura 1: Esquema mostra o contexto do material didático com proposta transmídia, tendo sua produção ao centro; na intersecção de todas as variáveis.

No livro impresso, os alunos entram em contato com o tema transversal por meio de conteúdos disciplinares a ele relacionados. Eles também têm acesso a esse conteúdo por meio do livro digital, que apresenta ferramentas de interação, como a possibilidade de linkar um site ao conteúdo, fazer marcações e comentários.

O livro digital apresenta ícones que direcionam professor e alunos para um pacote de objetos educacionais integrados, que é composto de: um audiovisual dinâmico de curta duração, que possibilita a introdução do tema da proposta dentro de uma abordagem transversal de questões pontuadas em duas ou mais disciplinas, e dois tipos de infográficos interativos, um multimídia que aprofunda o tema e os conteúdos trabalhados no livro impresso, e outro mais interativo e lúdico, com diferentes possibilidades a serem exploradas em sala de aula pelos alunos, com mediação do professor. A maioria dos infográficos interativos é multimodal, pois integram áudios, vídeos, animações e até materiais para imprimir, recortar e montar.

Para complementar o material, foi produzido um game para uso dos alunos. Kunigo é um jogo que possibilita experiências lúdicas e, ao mesmo tempo, apresenta conteúdos de forma multidisciplinar, unificando os eixos temáticos do ano e integrando conteúdos de diferentes disciplinas. 


\section{COMPOSIÇÃO DA PROPOSTA}

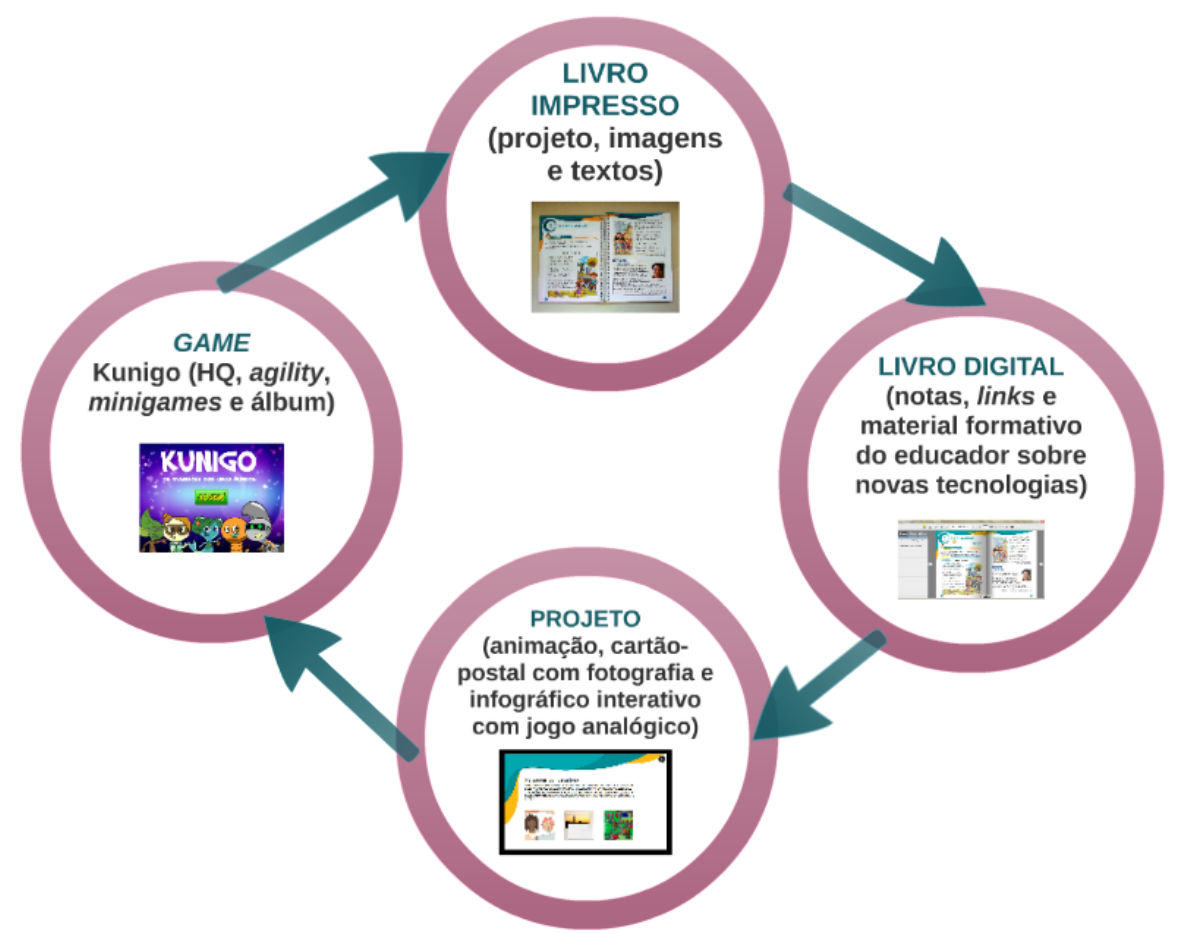

Figura 2: Apresentação do material didático com proposta transmídia produzido com conteúdos impressos e digitais contínuos e diferenciados. Cada etapa aborda diferentes mídias e suportes e não repetem conteúdo. Apesar da autonomia de cada etapa, sua totalidade permite um aproveitamento maior e, por isso, o uso, a participação e o engajamento de professores e alunos são necessários para a construção de sentido.

Assim, de forma resumida, são conteúdos para ver, ler, interagir, jogar e estudar. O conjunto de materiais educacionais, assim como as demais propostas transmídias, permite que educadores construam com seus alunos uma proposta de se trabalhar o tema e os conteúdos de diferentes formas, integradoras e em espiral, de forma adequada às suas realidades.

Espera-se que o uso do material de forma integrada possibilite: o desenvolvimento do processo de multiletramentos, ou seja, recursos que abarquem múltiplas linguagens e multissemioses, que sejam multimodais e levem em conta as múltiplas realidades; a integração entre os conteúdos das disciplinas, a partir de eixos temáticos; a experimentação contextualizada de determinados conceitos mais abstratos; um processo de ensino-aprendizagem mais instigante, lúdico, desafiador para alunos que cresceram em ambientes cercados pelo mundo digital; a contribuição para uma educação efetiva, complexa, que envolva princípios e valores, atitudes, comportamentos e demais elementos que levem os alunos a uma visão mais crítica do mundo à sua volta. 


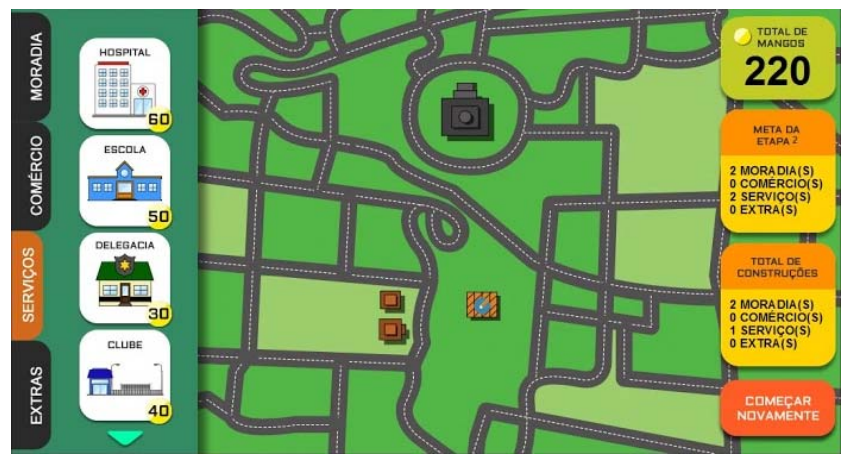

Figura 3: Imagem da tela do objeto educacional digital Construindo nosso bairro, infográfico interativo que integra o material do $2^{\circ}$ ano do Ensino Fundamental I. A tela final, quando impressa, torna-se o tabuleiro de um jogo proposto nas orientações ao professor, que tem como objetivo ampliar as discussões sobre o tema e colocar os conhecimentos dos alunos em prática de forma lúdica e dinâmica.

\section{CONSIDERAÇÕES FINAIS}

Ainda que a proposta de um material educacional transmídia apresentada esteja fundamentada em teorias que proponham uma real contribuição para novos modelos educacionais, que vão de encontro com as novas configurações da educação, a produção requer uma reestruturação para poder ser considerada uma proposta intuitiva e uma referência de material didático com integração de tecnologias.

Do ponto de vista pedagógico, por exemplo, há a necessidade de sistematizar as práticas escritas, de leitura e orais, ampliar as propostas de práticas de novos letramentos e, do ponto de vista da pedagogia de projetos, além de alinhar a proposta didático-pedagógica com a da coleção impressa para, assim, ser possível maior intersecção e utilização mais autônoma dos materiais.

Do ponto de vista do mercado editorial, comercial e econômico, torna-se imprescindível sistematizar e apresentar como um conjunto independente cada uma das propostas transmídias produzidas de modo a comercializá-las junto com as coleções impressas e, também, de forma autônoma.

Por fim, tendo em vista as atuais necessidades dos educadores e do quadro instável das editoras, torna-se necessário reunir todos os reforços para produzir diferentes materiais impressos e digitais que possibilitem o trabalho com os novos multiletramentos de modo a propor aos novos modelos educacionais outras metodologias de aprendizagem que integrem tecnologia. 


\section{REFERÊNCIAS}

BRASIL. Ministério da Educação. Secretária de Educação Básica. Diretoria de Currículos e Educação Integral. Diretrizes Curriculares Nacionais Gerais da Educação Básica. Brasília: MEC, SEB, DICEI, 2013.

BUZATO, Marcelo E. K. Letramento e inclusão na era da linguagem digital. São Paulo: IEL/UNICAMP, 2006.

GARCÍA-CANCLINI, Néstor. Consumidores e cidadãos: conflitos multiculturais da globalização. Rio de Janeiro: Editora UFRJ, 2006.

interculturalidade. Rio de Janeiro: ED UFRJ, 2005.

GRUPO DE NOVA LONDRES. A pedagogy of multiliteracies - Designing social futures. In COPE, B; KALANTZIS, M. (Eds.) Multiliteracies: Literacy learning and the design of social futures. London/NY: Routledge, 2006 [2000/1996]. P. 9-37.

JENKINS, Henry. Cultura da convergência. 2 ed. São Paulo: Aleph, 2009.

LANKSHEAR, C.; KNOBEL, M. Sampling "the New" in New Literacies. In: KNOBEL, M.; LANKSHE-AR, C. (Org.). A New Literacies Sampler. New York: Peter Lang, 2007.

LEMKE, Jay. Letramento metamidiático: transformando significados e mídias. Trab. linguist. apl. [online], v. 49, n. 2, 2010.

PRENSKY, Marc. Digital Natives, Digital Immigrants. MCB Press, 2001.

ROJO, Roxane; MOURA, Eduardo (Org.). Multiletramentos na escola. São Paulo: Parábola Editorial, 2012.

SILVA, Marco. Sala de aula interativa. 4. ed. Rio de Janeiro: Quartet, 2006.

\section{A AUTORA}

Camila de Castro Castilho é graduada em Letras pela USP (2005), pós-graduada em Jornalismo pela Fundação Cásper Líbero (2008) e mestre em Libros y Literatura Infantil y Juvenil pela Universitat Autònoma de Barcelona (2015). Atualmente é mestranda no IEL-Unicamp, na área de Linguagem e Educação, com pesquisa em propostas transmídias para produção de materiais didáticos digitais. É designer educacional e editora de conteúdos digitais.

E-mail: castro.mila@gmail.com 